\title{
Conservation status and management insights from tracking a cryptic and Critically Endangered species of Orchidaceae
}

\author{
T. KRAAIJ, J.A. BAARD and B. J. CRAIN
}

\begin{abstract}
Ninety-five percent of orchid species associated with fynbos shrublands of South Africa's Cape Floristic Kingdom have been assessed for the IUCN Red List, yet aspects of their demography and population biology remain poorly understood. We conducted a 6-year demographic study of the Critically Endangered Disa procera, a cryptic, terrestrial species from South Africa with a global population of c. 50 individuals known from a single location. We aimed to provide management recommendations that would facilitate its persistence. Our findings indicate that the population of $D$. procera is larger than previously thought, and the species occurs at two distinct locations. These orchids exhibit high interannual variation in population size and turnover of individuals, potentially indicative of a species with a short life span, and still meet the criteria for Critically Endangered status. The species benefits from disturbances, such as brush cutting along trails, or fire, which open up clearances in the vegetation. However, physical damage to plants during their aboveground growing season (September-January) is particularly detrimental and should be avoided in habitat management for the species. Fire had beneficial effects at the population and individual levels and is recommended at 10-25-year intervals, outside the orchid's growing season. The species exhibited comparatively high rates of fruit set $(68 \%)$, suggesting that pollination limitation does not currently constrain its performance. Its patchy distribution may, however, indicate constraints on dispersal or recruitment. We recommend that management strategies should include continued protection and monitoring of both populations, studies on pollination, habitat requirements and mycorrhizal associates, and a prescribed disturbance regime.
\end{abstract}

Keywords Cape Floristic Kingdom, Critically Endangered species, Disa procera, fire regime, fynbos shrubland, management strategies, non-destructive sampling, population biology

T. KraAi (Corresponding author) Nelson Mandela Metropolitan University, School of Natural Resource Management-Nature Conservation, Private Bag X6531, George, 6530, South Africa. E-mail tineke.kraaij@nmmu.ac.za

J. A. BAARD South African National Parks, Garden Route Scientific Services, Knysna, South Africa

B. J. CRAIN Department of Ecology and Evolutionary Biology, University of Tennessee, Knoxville, USA

Received 10 July 2015. Revision requested 25 August 2015

Accepted 23 February 2016. First published online 21 June 2016.
To view supplementary material for this article, please visit http://dx.doi.org/10.1017/So030605316000272

\section{Introduction}

7 he Cape Floristic Kingdom in South Africa is a global Liodiversity hotspot (Myers et al., 2000) that comprises one of the most unique and threatened orchid floras (McDonald, 1999; Linder et al., 2005). Endemism and rarity are common amongst Orchidaceae of the region (Stewart et al., 1982; Linder et al., 2005; Liltved \& Johnson, 2012); $69 \%$ are endemic and $23 \%$ are near-endemic (Liltved \& Johnson, 2012). Accordingly, 85 of the 89 orchid species associated with fynbos, a primary vegetation type of the region, are on the IUCN Red List (Raimondo et al., 2009). Nonetheless, relatively little is known about the fundamental ecology of many of the region's orchid species, and without this information it is difficult for conservation managers and policy makers to understand how these species will respond to threats, and how to make effective decisions when working to protect them.

Although for some orchid species rarity and endemism may be attributable to natural rarity (Stuckey, 1967), threats such as habitat loss or degradation, invasive exotic plants, illegal harvesting, and inappropriate burning regimes (mostly fire suppression) also play critical roles in the Cape Floristic Kingdom and elsewhere (Duncan et al., 2005; Raimondo et al., 2009; Bytebier et al., 2011; Whitman et al., 2011; Crain \& Tremblay, 2012). In temperate areas such as South Africa, the USA and Australia, for example, appropriate burning regimes are particularly important for many orchid populations, as regularly occurring fires are known to be beneficial for a number of species in terms of reproduction and population growth (Bowles, 1983; Bytebier et al., 2007, 2011; Coates \& Duncan, 2009; Lamont \& Downes, 2011). Fire is known to have a positive effect on orchid populations, as it removes competing vegetation, releases nutrients and reduces harmful fungi and other pests and pathogens (Stuckey, 1967; Stewart et al., 1982; Coates \& Duncan, 2009; Liltved \& Johnson, 2012). In South Africa several species of Disa P.J. Bergius orchids, a charismatic group from the region, reproduce only after fires (Bytebier et al., 2011). Consequently, it is critical that the effects of fire are assessed when making management 
decisions for rare and threatened orchid species in places such as the Cape Floristic Kingdom.

Despite the high level of rarity and threat pertaining to orchids of the Cape Floristic Kingdom, including many species of Disa, aspects of their demographics and the driving forces behind them are little studied and are mostly inferred from analyses undertaken elsewhere (e.g. Stuckey, 1967; Mehrhoff, 1983, 1989; Hutchings, 1987a,b). In terms of southern African orchids in general, the published literature focuses on topics such as taxonomy and biogeography (Johnson \& Bond, 1992; Steiner et al., 1994; Linder et al., 2005; Liltved, 2008; Bytebier et al., 2011; Johnson et al., 2013), and comprehensive information on the population biology of many species is lacking. However, a sound understanding of the population biology of rare or threatened species is a requisite for most conservation management efforts (Dixon \& Cook, 1989), and a lack thereof is considered a threat to a species' persistence (Raimondo et al., 2009).

Accordingly, we studied the population dynamics and habitat attributes of Disa procera H.P. Linder, a Critically Endangered terrestrial orchid associated with fynbos shrublands along the southern Cape coast of South Africa, to obtain information critical for the development of an effective conservation strategy for the species. At the last assessment of the species (Von Staden \& Turner, 2012) D. procera was known from only a single location $<_{3} \mathrm{~km}^{2}$ in extent and had a global population of $\mathrm{c} .50$ individuals. The main pressures leading to the decline of this species have been habitat transformation as a result of coastal development, agricultural expansion and plantation forestry (Von Staden \& Turner, 2012). Furthermore, the population continues to face threats from inappropriate vegetation management actions (e.g. a lack of, or excessive, disturbance from fires, herbivores and brush-cutting along roads and trails; illegal collection; and invasive alien plants; TK, JB, pers. obs.). Consequently, the species is categorized as Critically Endangered on the IUCN Red List, based on its limited extent of occurrence and continuing declines in its area of occupancy and in the number of mature individuals in the population, and because it occurs at only a single location (IUCN criteria B.1.a \& B.1.b(iii, v), B.2.a \& B.2.b(iii, v), and C.2.a(ii); Von Staden \& Turner, 2012). Too little is known about the ecology of $D$. procera to know what constitutes optimal environmental conditions for its persistence and proliferation.

Disa procera is a slender, tuberous geophyte with narrow, linear, upright leaves arranged in a rosette. Individual plants can reach c. $60 \mathrm{~cm}$ in height. Reproductive individuals have cerise flowers arranged in a lax raceme (Kurzweil, 2012). The aboveground vegetative growing season commences in early spring (September), flowering occurs during OctoberNovember, and capsules develop during November and early December. By January, plants have dried out and are no longer detectable. The species' cryptic stature (it is slender, delicate and grass-like in appearance) makes vegetative individuals practically indistinguishable from sympatric grasses and sedges when flowers are not present. Furthermore, individuals are difficult to mark because handling or tagging them can cause damage (particularly to underground portions). The species' transient nature presents a considerable challenge to its study.

Monitoring of $D$. procera is therefore confined to flowering individuals, in which form the species is identifiable and distinctive from congeners. Prior to initiation of the study, surveys conducted by a group of volunteer citizen scientists experienced in plant identification (the Custodians of Rare and Endangered Wildflowers) indicated that the total population of $D$. procera comprised c. 50 flowering individuals during any particular growing season. All individuals occurred in 4-7 sub-locations (depending on the survey year), most of which were associated with some form of disturbance (e.g. trails and clearing) that reduced aboveground vegetation cover.

Given the rare and threatened status of $D$. procera, the primary objective of our study was to perform an up-to-date survey of the species, to evaluate its demographic attributes and trends, and to determine how it is affected by habitat management. We were particularly interested in exploring how fire may influence the health and recovery of the species, given ongoing changes in natural burning regimes where it occurs. Accordingly, our specific aims were to (1) record the current size of the population of $D$. procera, and assess interannual variation in the number of individuals and overall growth rates, (2) quantify measures of plant vigour and fecundity as indicators of population performance, and assess if these measures vary through time, and (3) examine the effects of fire on plant vigour and fecundity as well as on population growth rates and persistence probabilities. Ultimately we endeavoured to offer management recommendations that would facilitate optimal population performance and thus perseverance of this Critically Endangered species.

\section{Study area}

Disa procera occurs along the southern Cape coast of South Africa. Its exact locality is not disclosed here, to prevent unscrupulous visitation, disturbance and collection of plants. Vegetation at the study site comprises southern Cape dune fynbos, a mixture of sandplain fynbos and subtropical thicket (Mucina \& Rutherford, 2006). Fragmentation and isolation of remaining undisturbed vegetation in the region and suppression of natural fires in the surrounding landscape have resulted in altered patterns of fire ignition and spread, and a general lack of fire at the study site (Kraaij et al., 2011). The agency currently managing the study area does not routinely implement prescribed burning but 
undertakes trail maintenance approximately every 3 months, during which time brush cutting occurs. Thus, the only known population of $D$. procera is confined to a site that is regularly altered and disturbed by human activities.

\section{Methods}

We focused our survey efforts on previously identified sublocations to cover the entire known flowering population, but each year the authors and the group of volunteer citizen scientists conducted additional searches for flowering individuals outside the known occurrences. We documented the entire detectable flowering population each year during 2009-2014, both during the peak flowering season (the end of October) and at the culmination of fruit development (the beginning of December). At each sub-location where multiple plants occurred together we recorded their exact locations as distances at right angles to, and along, permanently marked line transects. Where individuals occurred in groups of fewer than five we marked plants with metal pins $30 \mathrm{~cm}$ away from their stems in a specified compass direction. Geographical coordinates were recorded for all line transects and for individual plants marked with metal pins. By marking the flowering individuals we were able to relocate them during the subsequent fruiting period or during the next annual survey if they flowered again.

To assess turnover in individuals among years we calculated Sørensen similarity coefficients (Sørensen, 1948) for the population for all combinations of years. We also calculated the growth rate of the flowering population $(\lambda)$ each year as the number of flowering individuals recorded during the survey year $\left(N_{t+1}\right)$ divided by the number of flowering individuals recorded during the previous survey $\left(N_{t}\right)$ (Morris \& Doak, 2002). We then calculated the mean growth rate $\left(\lambda_{G}\right)$ as the geometric mean of the annual rates. We used the values of $\lambda$ calculated for each year to project the sizes of flowering populations over the next 10 years. To accomplish this we multiplied the size of flowering population by randomly selected values of $\lambda$ each year for a period of 10 years. We performed 1,00o iterations of this process and calculated the mean flowering population size and the standard deviation for each year of the simulation. Furthermore, for each year we calculated extinction probabilities as the number of iterations out of 1,000 in which the flowering population size fell below zero. Demographic analyses were conducted using the PopTools add-on in Microsoft Excel (Hood, 2010).

During surveys conducted in peak flowering periods we also recorded a number of physical attributes of each individual. We measured the aboveground height of each flowering plant, and recorded the total number of flowers on each plant.
One month later, during fruiting periods, we revisited each plant and recorded the number of developed seed capsules. With this information we quantified the rate of fruit set per plant (calculated as the percentage of flowers developing into capsules). To understand causes of reproductive failure we distinguished cases of physical damage to plants resulting in severance of the entire raceme and thereby preventing fruit set (referred to as damaged plants) from failure to set seed in intact plants (probably indicative of pollination failure). Damage to plants may have resulted from natural factors (e.g. animal activity), flower picking by people, or trail maintenance (in the form of brush cutting) carried out during the species' aboveground growth phase. We therefore evaluated each individual for signs of physical damage resulting in raceme removal by means other than normal senescence. We used Spearman rank correlations to investigate relationships between the mentioned measures of fecundity, and we used Mood's median test to detect differences in these measures among years, given that the data for these measures were not normally distributed. For comparisons of fecundity measures between two groups (e.g. damaged vs undamaged plants) we used Wilcoxon tests.

To assess the effects of fire, given that the vegetation had not burnt in over 30 years and had become moribund, prescribed burning was undertaken in a portion of the study site during February and April 2012 in an attempt to stimulate growth of the study species. This facilitated the best possible assessment of the effects of fire on the population because the limited population size, the species' small area of occurrence, and its zero tolerance for mortality resulting from sampling precluded more extensive or replicated experimentation. To determine if the burn had an effect on population size, we compared the numbers of flowering plants in the burnt area during the 3 post-fire years with the numbers in the unburnt area during the same period, expressed as proportions of the mean population sizes in each of the two areas during the 3 pre-fire years. A $\chi^{2}$ test was used to compare these relative population sizes in the burnt and unburnt areas during the post-fire years (20122014), correcting for the effect of damage by other causes. Furthermore, we calculated annual growth rates $(\lambda)$, as before, for the subsets of the flowering population that were burnt and unburnt so that the growth rates in each group could be compared. We also projected the mean population sizes and standard deviations over 10 years for each group. Likewise, we calculated annual extinction probabilities for flowering plants in each group.

To investigate the effects of fire on measures of plant vigour and fecundity (plant height, number of flowers, and number of capsules) we employed a Wilcoxon test, comparing pre- and post-fire plant performance in the burnt and unburnt areas, respectively. Statistical analyses were performed in StatGraphics Centurion XVII (Statpoint Technologies Inc., Warrenton, USA). 


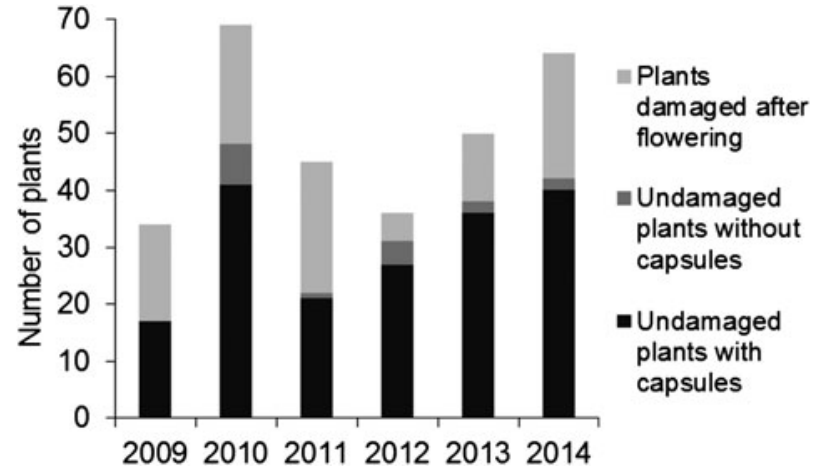

FIG. 1 Total numbers of Disa procera plants recorded per annum during 2009-2014, categorized according to whether the plants were undamaged and produced seed capsules, undamaged but failed to produce seed capsules, and damaged after flowering, and thus unable to produce seed capsules.

\section{Results}

During the study period we recorded 299 occurrences (plant $\times$ year combinations) of $D$. procera, comprising 193 individuals (Supplementary Fig. S1). At the original site where $D$. procera was known to occur the annual flowering population size was $34-70$ individuals (coefficient of variation among years $=29 \%$; Fig. 1 ). The median annual flowering population was 48 individuals. The smallest numbers of individuals were recorded during 2009 and 2012, both years in which trail maintenance was done during the species' aboveground growth phase (see Methods). A second population of c. 150 individuals was discovered by volunteers in a suburban area a few kilometres from the study site. As this population was discovered in the final year of the study, however, no physical or demographic data could be collected from these individuals and they were not included in further analyses presented here.

Turnover in flowering (i.e. detectable) individuals was high among years (Supplementary Fig. S1), with only four plants encountered four times during the 6-year study period, 22 plants encountered three times, and 51 plants encountered twice. The mean similarity in individuals among all years (i.e. the likelihood of a plant being reencountered in any other year) was $19 \%(n=15)$. The mean similarity between populations occurring in consecutive years was $36 \%(n=5)$, between those occurring 2 years apart $17 \%(\mathrm{n}=4)$, and between those occurring 3 years apart $7 \%(\mathrm{n}=3)$. Therefore the likelihood of a plant reappearing declined with increasing time after first detection.

In terms of population growth the overall number of flowering individuals increased in the time between the initial survey and the final survey (Fig. 1). Annual population sizes (mean $49.8 \pm$ SD 14.6, range 34-70) and annual population growth rates $\left(\lambda_{G}=1.13 \pm \mathrm{SD} 0.54\right.$, range $\left.0.65-2.02\right)$ were highly variable, however. The population projections indicate that on average the overall flowering population is

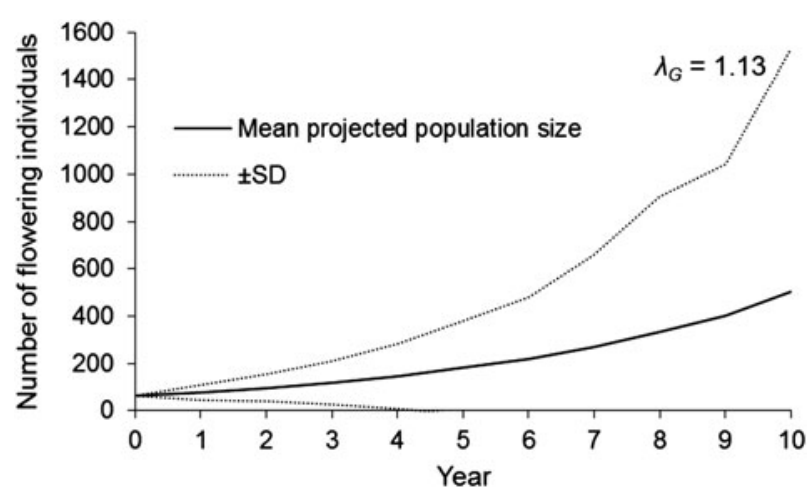

FIG. 2 Projected trend of the entire flowering population of Disa procera over 10 years. The starting population size was based on the total number of flowering individuals recorded during the final survey of this analysis, in 2014. Projected population sizes $( \pm S D)$ are based on mean values from 1,ooo iterations of population projections calculated using randomly selected values of $\lambda$, which were calculated from observed annual growth rates in the population.

expected to increase over the next 10 years (Fig. 2). Nevertheless, stochasticity in the projected population sizes as a result of variation in annual growth rates suggests that the population also has significant potential to reach zero flowering individuals in $<10$ years.

In terms of attributes of the plants themselves, median plant height during the study period was $40.0 \mathrm{~cm}$ (range $19.5-76.0 \mathrm{~cm}, \mathrm{n}=299$ ). Plant height was relatively stable among years, except in 2012 and 2013, when plants were significantly smaller than in most other years (Fig. 3; Table 1). The median number of flowers per plant was 11 (range 1-31, $\mathrm{n}=$ 299; Fig. 3) and did not differ significantly among years (Table 1). A third of all recorded plants were damaged after the survey of flowering, and were thus unable to produce capsules. Damaged plants $(\mathrm{n}=100)$ did not differ significantly from undamaged plants $(n=199)$ in terms of height or the number of flowers per plant (Table 1). The median number of seed capsules per undamaged plant was seven (range $0-29, \mathrm{n}=199$ ) and did not differ significantly among years (Fig. 3). The median proportion of capsule set (percentage of flowers developing into capsules per undamaged plant) differed significantly among years, with measures in 2009 and 2012 significantly lower than measures in 2010, 2013 and 2014 (pairwise comparisons lacked the power to identify significant between-group differences) (Fig. 3). In considering the total reproductive output of the population over the study period, $91 \%$ (182 of 199) of undamaged plants produced at least one capsule, and $68 \%$ of all flowers of undamaged plants developed into capsules.

The number of flowers $\left(r_{\mathrm{s}}=0.61, \mathrm{P}<0.001\right)$ and capsules $\left(r_{\mathrm{s}}=0.38, \mathrm{P}<0.001\right)$ per plant were both significantly correlated with plant height, and the number of capsules was significantly correlated with the number of flowers $\left(r_{\mathrm{s}}=0.63, \mathrm{P}<0.001\right)$. The proportion of fruit set was not 

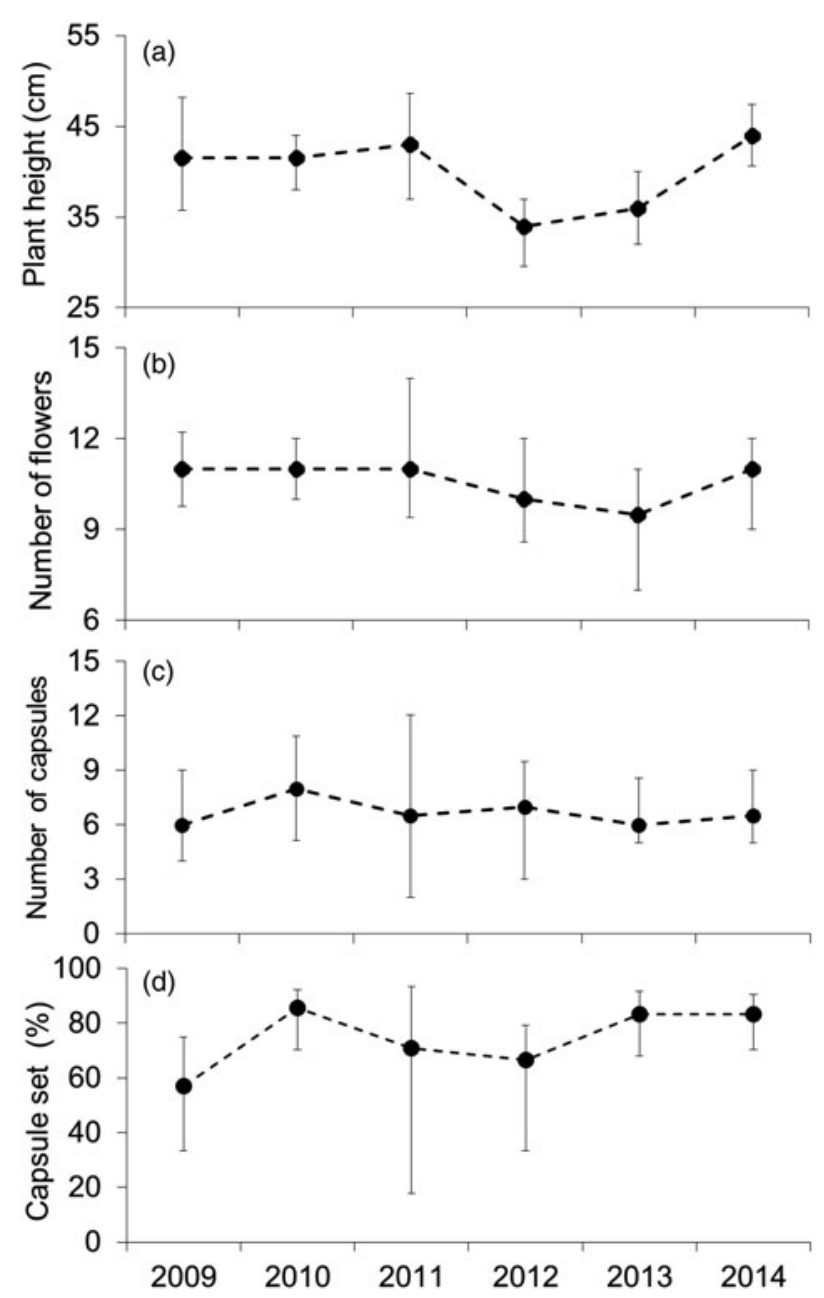

FIG. 3 Annual medians of (a) plant height (all plants), (b) number of flowers per plant (all plants), (c) number of capsules per plant (undamaged plants only), and (d) percentage capsule set (percentage of flowers developing into capsules per undamaged plant). Error bars indicate $95 \%$ confidence limits based on Mood's median test order statistics (Table 1).

significantly correlated with plant height $\left(r_{\mathrm{s}}=0.01\right.$, $\mathrm{P}=0.815)$ or number of flowers per plant $\left(r_{\mathrm{s}}=-0.02\right.$, $\mathrm{P}=0.752$ ).

Results from the post-burn surveys indicated that fire had an effect on several of the variables measured. We recorded an increase in the population size of orchids in the burnt area (Fig. 4). During the first 3 post-fire years the number of plants in the burnt area as a proportion of that prior to the burn was significantly higher than expected based on a comparison with the unburnt area (Table 1). Fire also corresponded with an increase in observed population growth rates: mean rates increased in the burnt population after the fire $\left(\lambda_{G}=1.00 \pm \mathrm{SD} 0.67\right.$ pre burn; $\lambda_{G}=1.38 \pm \mathrm{SD} 0.67$ post burn). In contrast, population growth rates decreased in the unburnt population after fire ( $\lambda_{G}=1.22 \pm$ SD 1.14 pre burn; $\lambda_{G}=0.98 \pm$ SD 0.96 post burn).

Population projections for plants on burnt vs unburnt sites supported results demonstrating the benefits of fire.
On the burnt site, projections of population sizes after 10 years were smaller when based on observed growth rates of plants before the burn (mean $=31 \pm$ SD 55; Fig. 5a) than when based on observed growth rates of plants after the burn (mean $=1,499 \pm$ SD 2,259; Fig. 5b). Conversely, on the unburnt sites, population projections were larger when based on observed growth rates prior to the burn (mean $=2,283 \pm$ SD 6,387; Fig. 6a) than after the burn (mean $=731 \pm$ SD 2,877; Fig. 6b). Thus, fire had a positive effect on predicted population sizes for the next 10 years.

Analyses of extinction probabilities for flowering individuals supported the results of the population projections. Projections for flowering plants on the burnt site based on observed annual growth rates from pre-burn years indicated there was a significant probability of reaching o individuals within 10 years ( $>5 \%$ of 1,000 iterations; Fig. $7 \mathrm{a}$ ), whereas projections based on observed annual growth rates from post-burn years showed markedly reduced probability of reaching o flowering individuals within 10 years (o\% of 1,000 iterations). Conversely, the population on the unburnt site had a low probability of reaching o flowering individuals within 10 years, based on projections using pre-burn growth rates ( $<1 \%$ of 1,000 iterations), whereas extinction probabilities increased ( $>16 \%$ of 1,000 iterations) when using growth rates from post-burn years (Fig. 7b).

Fire also had positive effects on some, but not all, measures of plant vigour (Table 1). Fire resulted in a significant increase in median plant height in the burnt area (pre burn $33.7 \mathrm{~cm}$, post burn $37.7 \mathrm{~cm}$ ), with a concomitant decrease in median plant height in the unburnt area (pre burn $45.7 \mathrm{~cm}$, post burn 38.0 $\mathrm{cm}$ ). Furthermore, the median number of flowers per plant declined in the unburnt area between the pre-burn (11.7 flowers) and post-burn (8.9) periods but did not change significantly (Table 1 ) over the same period in the burnt area (pre burn 12.4, post burn 11.0). No effect was detected in terms of the number of capsules produced per plant. Nevertheless, plants on the burnt site were larger and produced more flowers after the burn treatment than those on the unburnt site, and thus fire appeared to be beneficial to $D$. procera.

\section{Discussion}

Disa procera is a Critically Endangered, cryptic and transient orchid species, and therefore we employed nondestructive methods to mark and monitor these plants over successive years to help improve management efforts for the only known extant populations. Given the overall rarity of the species, very little disturbance from survey and sampling techniques could be permitted. The methods employed facilitated evaluation of the current status of the species, and projection of its future demographic trends.

Our results confirmed that the study species has a diminutive population size but revealed that it comprises 
TABLE 1 Test results of the effects of year (2009-2014), damage from various causes, and fire (in early 2012) on various measures of Disa procera.

\begin{tabular}{|c|c|c|c|c|}
\hline Measure & Effect & Test & Test statistic & Direction of effect \\
\hline Plant height & Year & Mood's & $30.5^{\star * *}$ & See Fig. 3 \\
\hline Number of flowers per plant & Year & Mood's & 5.6 & \\
\hline Number of capsules per undamaged plant & Year & Mood's & 4.1 & \\
\hline Rate of capsule set & Year & Mood's & $91.5^{\star * *}$ & See Fig. 3 \\
\hline Plant height & Damaged vs undamaged & Wilcoxon & $9,102.0$ & \\
\hline Number of flowers per plant & Damaged vs undamaged & Wilcoxon & $9,477.0$ & \\
\hline Number of plants during post-fire years 2012-2014 & Burnt vs unburnt area & $\chi^{2}$ & $320.6^{*}$ & Burnt $>$ unburnt \\
\hline Plant height in unburnt area & Pre fire vs post fire & Wilcoxon & $4,688.0^{\star *}$ & Pre fire $>$ post fire \\
\hline Plant height in burnt area & Pre fire vs post fire & Wilcoxon & $1,343.0^{*}$ & Post fire $>$ pre fire \\
\hline Number of flowers per plant in unburnt area & Pre fire vs post fire & Wilcoxon & $4,641.0^{\star *}$ & Pre fire $>$ post fire \\
\hline Number of flowers per plant in burnt area & Pre fire vs post fire & Wilcoxon & $1,856.5$ & \\
\hline Number of capsules per plant in unburnt area & Pre fire vs post fire & Wilcoxon & $1,988.5$ & \\
\hline Number of capsules per plant in burnt area & Pre fire vs post fire & Wilcoxon & 538.5 & \\
\hline
\end{tabular}

Significantly different at ${ }^{*}, \mathrm{P}<0.05 ;{ }^{* *}, \mathrm{P}<0.01 ;{ }^{* * *}, \mathrm{P}<0.001$

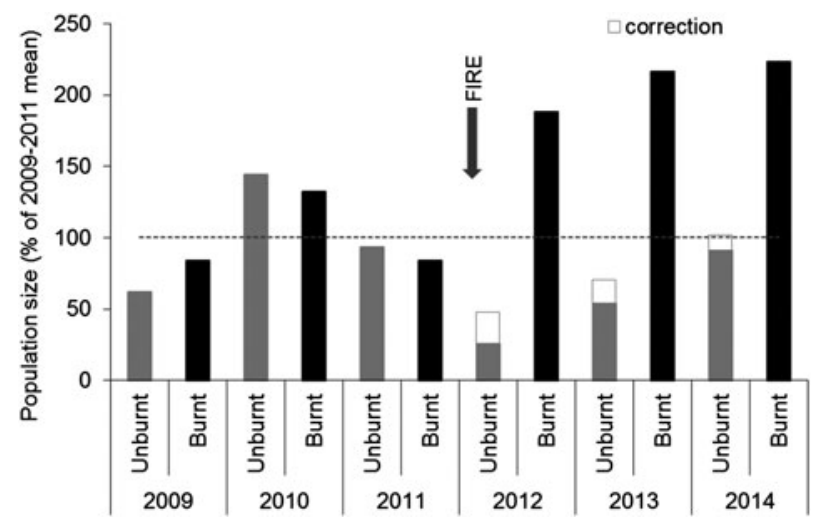

FIG. 4 The annual population size of Disa procera in the areas burnt and unburnt in the 2012 fire. Population size is expressed as a percentage of the mean number of plants occurring during the pre-fire years 2009-2011 in the burnt and unburnt areas. An estimated correction (based on field notes of plant locations where there was noticeable mechanical disturbance) is shown for the effect of brush cutting during 2012 in the unburnt area.

two subpopulations, one of which was undocumented prior to our surveys. The existence of a second subpopulation at a distinct location considerably enhances the species' prospects for persistence, although the current Red List categorization of Critically Endangered remains applicable because of the limited area of occupancy, fragmentation and decline in quality of the habitat, and the small size of the overall population. Thus, protection and appropriate management of the new site must be a priority.

The subpopulation that was the focus of this analysis is subject to high interannual variation in total size. High turnover of individuals among years and decreasing likelihood of plant reappearance over time suggests that the species has a relatively short life span (cf. Hutchings, 1987a), although our evidence is limited to the 6-year study period. Notably, however, flower production by individual plants

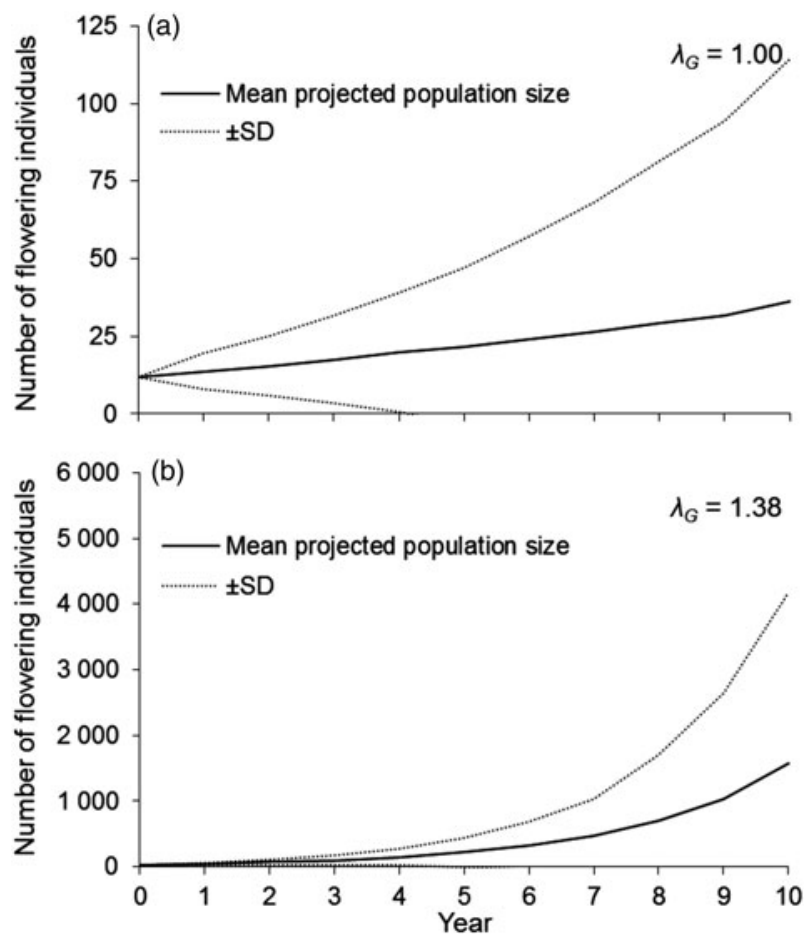

FIG. 5 Projected sizes of the flowering population of Disa procera on the burnt site over 10 years. Starting population sizes were based on the total number of flowering individuals recorded (a) prior to the burn treatment (during the 2011 survey) and (b) after the burn treatment (during the 2014 survey). Projected population sizes $( \pm S D)$ are based on mean values from 1,000 iterations of population projections calculated using randomly selected values of $\lambda$, which were calculated from observed annual growth rates in the population before or after the burn treatment.

was not predictable over successive years, and because our surveys were limited to flowering plants this suggests that the total population size could exceed the mean annual 


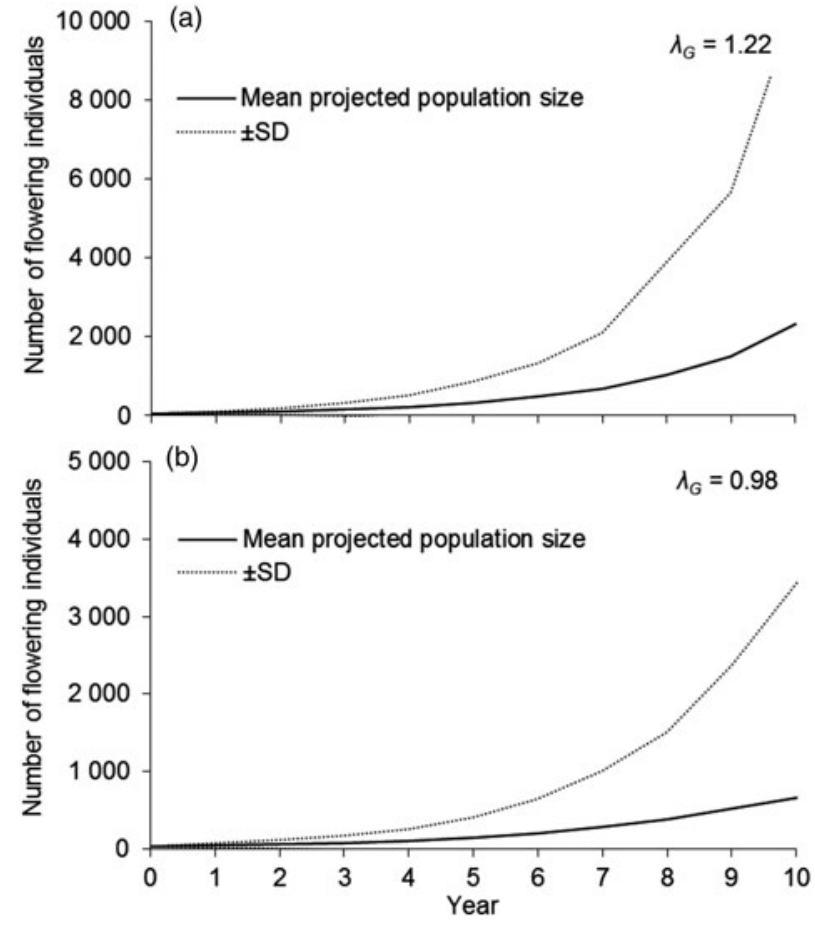

FIG. 6 Projected sizes of the flowering population of Disa procera on the unburnt site over 10 years. Starting population sizes were based on the total number of flowering individuals recorded (a) prior to the burn treatment (during the 2011 survey) and (b) after the burn treatment (during the 2014 survey). Projected population sizes $( \pm S D)$ are based on mean values from 1,000 iterations of population projections calculated using randomly selected values of $\lambda$, which were calculated from observed annual growth rates in the population before or after the burn treatment.

size of the detectable aboveground population. Although monitoring all life stages of this species could improve our understanding of its demographics, aboveground markers to obtain such data are undesirable as metal pins can damage underground plant parts and increase the visibility of plants that are already prone to illegal collection. Nevertheless, the number of reproductive individuals in the study population is an important indicator of the overall health of the species as these individuals are responsible for future recruitment. Accordingly, continued monitoring of reproductive individuals is an important management protocol.

Encouragingly, fruit set recorded for the study species (68\% of flowers producing capsules) was comparable to or higher than that of many other South African orchids (Disa ferruginea c. $70 \%, D$. atricapilla c. $65 \%, D$. bivalvata c. $62 \%$, D. uniflora c. $46 \%$, D. grandiflora c. $6 \%$, Herschelianthe graminifolia c. 63\%; Johnson \& Bond, 1992; Johnson, 1993, 1994; Steiner et al., 1994), and higher than the global mean for natural fruit set in non-autogamous orchids (23.1 \pm SE 6.6\%; Tremblay et al., 2005). Orchids are scarce in fynbos
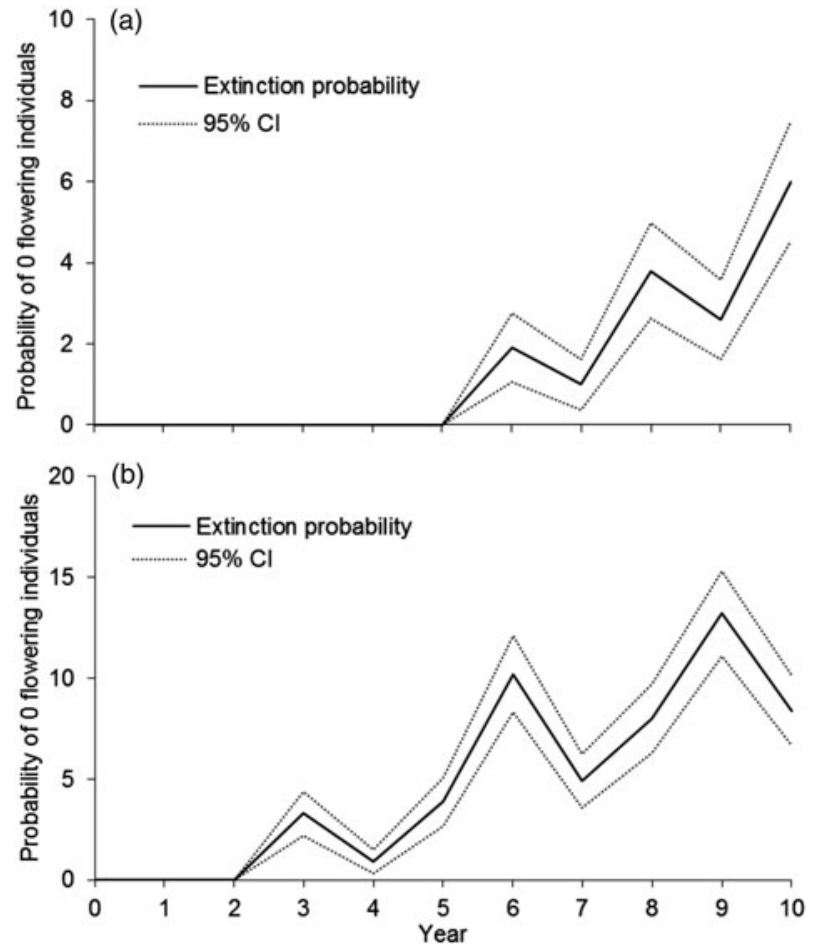

FIG. 7 Projected extinction probabilities over 10 years for flowering individuals of Disa procera on (a) the burnt site, based on observed annual growth rates from pre-burn years and (b) the unburnt site, based on observed annual growth rates from post-burn years. Probabilities are calculated as the number of times the population reached zero flowering plants out of 1,000 iterations for each year.

fragments isolated by surrounding indigenous forest in the southern Cape, possibly as a result of pollinator limitation (Bond et al., 1988). Our study site is similarly isolated from larger stretches of fynbos but given the study species' comparatively high rate of seed set it is unlikely that a lack of pollination currently constrains population growth. The pollinators of $D$. procera are unconfirmed; a brown monkey beetle Pachycnema marginella was observed inside a flower and may contribute to pollination but the species is probably adapted for bee pollination (Johnson \& Steiner, 1994; Johnson et al., 1998; Steiner, 1998; S.D. Johnson, pers. comm., 9 January 2015) and more information is needed to determine if pollinator presence is truly a limiting factor.

There are several alternative explanations for the scarcity of $D$. procera. One explanation may be the aged and overgrown nature of the vegetation where $D$. procera occurs. Likewise, the species' patchy distribution and absence from considerable tracts of seemingly suitable habitat, even within the study area (authors, pers. obs.), may indicate constraints to dispersal, recruitment or symbiotic mycorrhizae.

Furthermore, physical damage to plants during their aboveground growing season may be limiting the recovery of these orchids. Plant heights were significantly reduced 
in 2012 when brush cutting occurred late into the growing season, potentially with a legacy effect in 2013. Brush cutting in 2009 and 2012 during the vegetative growth phase and prior to flowering also coincided with the smallest recorded population sizes and suppressed rates of fruit set within those seasons. Damage incurred between the flowering and fruiting stages through brush cutting and other agents likewise had a negative effect on the proportion of fruit set of damaged individuals and thus the potential for population growth. Nevertheless, brush cutting at appropriate times is beneficial to some orchids and could have a positive impact on D. procera as well (Steiner, 1998).

The study species' close association with hiking trails also predisposes it to flower picking and illegal collection and could hinder its recovery. However, damaged and undamaged plants were not discernible on the basis of plant height or number of flowers per plant, which suggests that the agents responsible for damage were impartial to plant size or showiness.

The local fauna could also be contributing to the scarcity of $D$. procera, as animal activity was often evident (e.g. shallow soil disturbance and severance of racemes a few centimetres aboveground) in the immediate vicinity of study plants. These signs suggest that flowers may have been damaged and removed by tortoises and rodents, including porcupines Hystrix africaeaustralis and dune mole-rats Bathyergus suillus, which are abundant in the area. These animals can also disturb topsoil and possibly harm underground plant parts that are important during dormancy periods. Damage to flowers and seed capsules by invertebrates was also common in the study population. It is likely that plants were damaged to varying degrees by a variety of herbivorous animals, and future analyses on the effects of the local fauna could be beneficial to managers.

Despite the limitations and disturbances that threaten $D$. procera, our results indicate that fire has a favourable effect on the species at the population and individual levels, an outcome that is in line with evidence from other studies (Stuckey, 1967; Stewart et al., 1982; Bytebier et al., 2007, 2011; Coates \& Duncan, 2009; Lamont \& Downes, 2011). Like many other orchids, $D$. procera seems to benefit from disturbances that create open and well-lit conditions, as evident from its habit of growing along trails and its enhanced performance after fires. Accordingly, prescribed burns could be an important management strategy for this species. However, because physical damage to the plants during their aboveground growing season is particularly detrimental, management agencies should refrain from any activity (including trail maintenance and prescribed burning) that may cause disturbance to the species' habitat during its aboveground growing season (September-January). Although disturbances may enhance growing conditions, inappropriate timing and types of disturbances may have dire consequences and potentially affect the population's performance over successive years (Stuckey, 1967; Stewart et al., 1982; Willson et al., 2006). In the absence of naturally occurring fires, however, prescribed burning (outside the orchid's growing season) is advisable at intervals of 10-25 years and intensities characteristic of the natural disturbance regime in coastal fynbos (Kraaij et al., 2013). These prescribed burns should have a positive impact on plant vigour, flower production and population growth rates, and significantly bolster the recovery of the species.

Despite high levels of flower production, high capsule set, and projections suggesting the population should be increasing over time, the population remains extremely small, and accordingly conservation managers need to consider carefully the various factors that could be limiting the population size. The existence of an additional subpopulation potentially facilitates more manipulative studies of the effects of brush cutting, fire and other factors that may be limiting D. procera. Analysis of dormancy periods, mycorrhizal associates, soil seed banks and seed longevity should also help to elucidate remaining uncertainties regarding the species' longevity, turnover of individuals, recruitment and the role of vegetative reproduction (Tamm, 1972; Stewart et al., 1982; Hutchings, 1987a,b; Whigham et al., 2006). Consequently, in addition to the management strategies recommended based on the results of this study, we advocate further studies of this species along with continual monitoring of both populations to ensure full species recovery. Overall, the species' small global population, the large interannual variance in its population size, the short life span of individual plants, and the improbable existence of a longlived soil seed bank (Whigham et al., 2006) all increase the species' susceptibility to extinction, and proactive management efforts will be necessary to increase the likelihood of this species' long-term survival.

\section{Acknowledgements}

South African National Parks funded this research. We thank Ismail Ebrahim (Threatened Species Programme, South African Biodiversity Institute) for initial assistance with development of the field survey protocol; the dedicated Outramps group of the Custodians of Rare and Endangered Wildflowers for assistance with in-field searches for additional plants, and the discovery of a second population of the study species; and protected-area management staff for undertaking prescribed burning.

\section{References}

Bond, W.J., Midgley, J. \& Vlok, J. (1988) When is an island not an island? Insular effects and their causes in fynbos shrublands.

Oecologia, 77, 515-521.

Bowles, M.L. (1983) The tallgrass prairie orchids Platanthera leucophaea (Nutt.) Lindl. and Cypripedium candidum Muhl. ex 
Willd.: some aspects of their status, biology, and ecology, and implications toward management. Natural Areas Journal, 3, 14-37.

Bytebier, B., Antonelli, A., Bellstedt, D.U. \& Linder, H.P. (2011) Estimating the age of fire in the Cape flora of South Africa from an orchid phylogeny. Proceedings of the Royal Society B, 278, 188-195.

Bytebier, B., Oliver, E.G.H. \& Liltved, W.R. (2007) Disa linderiana (Orchidaceae), a new orchid from the Western Cape of South Africa. South African Journal of Botany, 73, 558-562.

Coates, F. \& Duncan, M. (2009) Demographic variation between populations of Caladenia orientalis - a fire-managed threatened orchid. Australian Journal of Botany, 57, 326-339.

Crain, B.J. \& Tremblay, R.L. (2012) Update on the distribution of Lepanthes caritensis, a rare Puerto Rican endemic orchid. Endangered Species Research, 18, 89-94.

Dixon, P.M. \& CoOK, R.E. (1989) Science, planning, and the recovery of endangered plants. Endangered Species UPDATE, 6, 9-14.

Duncan, M., Pritchard, A. \& Coates, F. (2005) Major threats to Endangered orchids of Victoria, Australia. Selbyana, 26, 189-195.

Hood, G.M. (2010) PopTools version 3.2.5. Http://www.poptools.org.

Hutchings, M.J. (1987a) The population biology of the early spider orchid, Ophrys sphegodes Mill. I. A demographic study from 1975 to 1984. Journal of Ecology, 75, 711-727.

Hutchings, M.J. (1987b) The population biology of the early spider orchid, Ophrys sphegodes Mill. II. Temporal patterns in behaviour. Journal of Ecology, 75, 729-742.

Johnson, S.D. (1993) Carpenter bee pollination of Herschelianthe graminifolia (Orchidaceae) on the Cape Peninsula. Flora, 188, 383-386.

Johnson, S.D. (1994) Evidence for Batesian mimicry in a butterfly-pollinated orchid. Biological Journal of the Linnean Society, 53, 91-104.

Johnson, S.D. \& Bond, W.J. (1992) Habitat dependent pollination success in a Cape orchid. Oecologia, 91, 455-456.

Johnson, S.D., Новвнанn, N. \& Bytebier, B. (2013) Ancestral deceit and labile evolution of nectar production in the African orchid genus Disa. Biology Letters, 9, 20130500.

Johnson, S.D. \& S Teiner, K.E. (1994) Pollination by megachilid bees and determinants of fruit-set in the Cape orchid Disa tenuifolia. Nordic Journal of Botany, 14, 481-485.

Johnson, S.D., Steiner, K.E., Whitehead, V.B. \& Vogelpoel, L. (1998) Pollination ecology and maintenance of species integrity in co-occurring Disa racemosa L.f. and Disa venosa SW. (Orchidaceae) in South Africa. Annals of the Missouri Botanical Garden, 85, 231-241.

Kraaij, T., Cowling, R.M. \& van Wilgen, B.W. (2011) Past approaches and future challenges to the management of fire and invasive alien plants in the new Garden Route National Park. South African Journal of Science, 107, article no. 633, 11 pp.

Kraaij, T., Cowling, R.M., van Wilgen, B.W. \& Schutte-Vlok, A.-L. (2013) Proteaceae juvenile periods and post-fire recruitment as indicators of minimum fire return interval in eastern coastal fynbos. Applied Vegetation Science, 16, 84-94.

Kurzweil, H. (2012) Orchidaceae. In Plants of the Greater Cape Floristic Region. 1: The Core Cape Flora (eds J. Manning \&

P. Goldblatt), p. 186. South African National Biodiversity Institute, Pretoria, South Africa.

LAmont, B.B. \& Downes, K.S. (2011) Ecology of plant resprouting in fire-prone ecosystems. Plant Ecology, 212, 2111-2125.

LiLtved, W.R. (2008) The 'moonlight acrolophia' recent observations on the orchid Acrolophia lunata, in the southern Cape Floristic Region. Veld \& Flora, 94, 72-73.

Liltved, W.R. \& Johnson, S.D. (2012) The Cape Orchids: A Regional Monograph of the Orchids of the Cape Floristic Region. Sandstone Editions, Noordhoek, South Africa.
Linder, H.P., Kurzweil, H. \& Johnson, S.D. (2005) The Southern African orchid flora: composition, sources and endemism. Journal of Biogeography, 32, 29-47.

McDonald, D.J. (1999) Montane flora of the southern Langeberg, South Africa: a checklist of the flowering plants and ferns. Bothalia, 29, 119-137.

Menrhoff, III, L.A. (1983) Pollination in the genus Isotria (Orchidaceae). American Journal of Botany, 70, 1444-1453.

Menrhoff, L.A. (1989) The dynamics of declining populations of an endangered orchid, Isotria medeoloides. Ecology, 70, 783-786.

Morris, W.F. \& DoAK, D.F. (2002) Quantitative Conservation Biology: Theory and Practice of Population Viability Analysis. Sinauer Associates, Inc., Sunderland, USA.

Mucina, L. \& Rutherford, M.C. (eds) (2006) The Vegetation of South Africa, Lesotho and Swaziland. Strelitzia, Volume 25. South African National Biodiversity Institute, Pretoria, South Africa.

Myers, N., Mittermeier, R.A., Mittermeier, C.G., Da Fonseca, G.A.B. \& KeNT, J. (2000) Biodiversity hotspots for conservation priorities. Nature, 403, 853-858.

Raimondo, D., von Staden, L., Foden, W., Victor, J.E., Helme, N.A., Turner, R.C. et al. (eds) (2009) Red List of South African Plants. Strelitzia, Volume 25. South African National Biodiversity Institute, Pretoria, South Africa.

Sørensen, T. (1948) A method of establishing groups of equal amplitude in plant sociology based on similarity of species content and its application to analyses of the vegetation on Danish commons. Biologiske Skrifter / Kongelige Danske Videnskabernes Selskab, 5, 1-34.

Steiner, K.E. (1998) The evolution of beetle pollination in a South African orchid. American Journal of Botany, 85, 1180-1193.

Steiner, K.E., Whitehead, V.B. \& Johnson, S.D. (1994) Floral and pollinator divergence in two sexually deceptive South African orchids. American Journal of Botany, 81, 185-194.

Stewart, J., Linder, H.P., Schelpe, E.A. \& Hall, A.V. (1982) Wild Orchids of Southern Africa. Macmillan, Johannesburg, South Africa.

STUCKey, I.H. (1967) Environmental factors and the growth of native orchids. American Journal of Botany, 54, 232-241.

TAMM, C.O. (1972) Survival and flowering of some perennial herbs. II. The behaviour of some orchids on permanent plots. Oikos, 23, 23-28.

Tremblay, R.L., Ackerman, J.D., Zimmerman, J.K. \& Calvo, R.N. (2005) Variation in sexual reproduction in orchids and its evolutionary consequences: a spasmodic journey to diversification. Biological Journal of the Linnean Society, 84, 1-54.

Von Staden, L. \& Turner, D. (2012) Disa procera H.P.Linder. National Assessment: Red List of South African Plants version 2014.1. Http://redlist.sanbi.org/redcat.php [accessed 30 May 2014].

Whigham, D.F., O’Neill, J.P., Rasmussen, H.N., Caldwell, B.A. \& McCormick, M.K. (2006) Seed longevity in terrestrial orchidspotential for persistent in situ seed banks. Biological Conservation, 129, 24-30.

Whitman, M., Medler, M., Randriamanindry, J.J. \& Rabakonandrianina, E. (2011) Conservation of Madagascar's granite outcrop orchids: the influence of fire and moisture. Lankesteriana, 11, 55-67.

Willson, G., Page, M.J. \& Akyuz, F.A. (2006) Precipitation and fire effects on flowering of a rare prairie orchid. Great Plains Research, $16,37-43$.

\section{Biographical sketches}

TinekE KRAalj's research interests include fynbos ecology, with emphasis on fire ecology in the eastern part of the Cape Floristic Kingdom, the biology of invasive alien plants, conservation of 
rare and threatened plant species, ecosystem restoration, and plant-herbivory interactions. Much of her research has applied value for biodiversity conservation in protected areas. JOHAN A. BAARD's research interests include indigenous forest and fynbos ecology, plant inventories, ecology of invasive alien plants, conservation of rare and threatened plant species, and the use of geographical information systems to document and analyse biodiversity patterns and processes. BENJAMIN J. CRAIN's primary research interests include conservation biology, ecology of threatened species, and biogeography. His research involves population viability modelling, spatial analyses, and biodiversity assessments, particularly for threatened species and their habitats. 